\title{
MicroRNA-340 inhibits tumor cell proliferation, migration and invasion, and induces apoptosis in hepatocellular carcinoma
}

\author{
ZIYAO WANG, DAN SONG and PING HUANG
}

\begin{abstract}
National Key Clinical Department, Department of Hepatobiliary Surgery, The First Affiliated Hospital of Chongqing Medical University, Chongqing Medical University, Chongqing 400000, P.R. China
\end{abstract}

Received January 8, 2017; Accepted July 28, 2017

DOI: $10.3892 / \mathrm{mmr} .2017 .7583$

\begin{abstract}
MicroRNAs (miRs) are short RNAs that serve a role in the origination and progression of hepatocellular carcinoma (HCC). miR-340 has been identified to be a novel tumor suppressor. The present study investigated the antitumor function of miR-340 in HCC. In the present study, it was detected that miR-340 was significantly decreased in HCC cancer tissues and human HCC cell lines using reverse transcription-quantitative polymerase chain reaction analysis. Cell Counting kit- 8 and apoptosis assays demonstrated that miR-340 reduced cell proliferation and induced cellular apoptosis in HCC cell lines. A Transwell invasion assay demonstrated that miR-340 suppressed the migration and invasion of HCC cell lines. In addition, S-phase kinase-associated protein 2 (SKP2), which may be repressed by miR-340 in HCC cell lines, was identified to be a potential target of miR-340. The results of the present study revealed that miR-340 serves a tumor suppressor role by influencing the proliferation, apoptosis, migration and invasion of HCC cell lines, which may be explained by the downregulation of SKP2 by miR-340.
\end{abstract}

\section{Introduction}

Liver cancer is one of the most common types of cancer in the world, with an estimated 782,500 new liver cancer cases and 745,500 mortalities occurring worldwide during 2012; 50\% of the total number of cases and mortalities were in China (1). The majority (70-90\%) of primary liver cancer cases worldwide are hepatocellular carcinoma (HCC) (2). The development of $\mathrm{HCC}$ is the result of a complex, multi-step process associated with genetic and epigenetic alterations $(3,4)$. Therefore, studies

Correspondence to: Professor Ping Huang, National Key Clinical Department, Department of Hepatobiliary Surgery, The First Affiliated Hospital of Chongqing Medical University, Chongqing Medical University, 1 Youyi Road, Yuzhong, Chongqing 400000, P.R. China

E-mail: huangpchina@sina.com

Key words: microRNA-340, hepatocellular carcinoma, proliferation, apoptosis, migration, invasion, S-phase kinase-associated protein 2 are required to elucidate the mechanism of $\mathrm{HCC}$, and novel strategies for early diagnosis, prediction of the prognosis, and treatment of patients.

More than 2,000 microRNAs (miRNAs/miRs) have been discovered in humans and they serve an important role in biological processes by post-transcriptionally regulating protein-coding genes (5). A number of studies have associated miRNAs with numerous functions in tumorigenesis, including cell proliferation, differentiation, apoptosis, invasion, metastasis, autophagy (6), epithelial-mesenchymal transition (EMT) (7), lipogenesis (8) and epigenetics (9). The involvement of miRNAs in HCC has been demonstrated; aberrant miRNA expression may affect a number of cancer-associated pathways, including cellular tumor antigen $\mathrm{p} 53$, Ras/mitogen-activated protein kinase, phosphatidylinositol 3-kinase/RAC- $\alpha$ serine/threonine protein kinase/protein kinase mTOR, Wnt/ $\beta$-catenin, and transforming growth factor- $\beta$ (10). Therefore, analysis of the dysregulation of miRNAs in HCC, and the interactions between targets proteins and miRNAs is of importance.

miR-340 has been identified to be a tumor suppressor in many types of tumor, including colorectal cancer (11), ovarian cancer (12) and breast cancer (13). According to previous studies, miR-340 exerts tumor inhibitory functions by suppressing proliferation, migration, invasion and inducing apoptosis $(13,14)$. Notably, it was reported that miR-340 impaired the growth of colorectal cancer by counteracting the Warburg effect (15); similarly, miR-340 may upregulate the expression of glucose transporter- 1 and result in an increase in lactate secretion and glucose uptake in oral squamous cell carcinoma (16). In the present study, the expression of miR-340 in HCC cell lines and clinically resected human HCC tissues was evaluated, in addition to investigating the biological function of miR-340 in HCC development. The roles of miR-340 in HCC development and the underlying mechanism were investigated. The results of the present study demonstrated that miR-340 inhibited HCC cell proliferation, migration and invasion, and induced apoptosis, in addition to downregulating the expression of S-phase kinase-associated protein 2 (SKP2), which may be a potential therapeutic application of miR-340 in patients with HCC.

\section{Materials and methods}

Ethics statement. All patients and their families agreed to participate in the present study and gave written informed 
consent. The present study was approved by the institutional ethics board of The First Affiliated Hospital of Chongqing Medical University (Chongqing, China) and complied with the Declaration of Helsinki.

Cell lines and cell culture. The human HCC cell lines SMMC-7721, Hep3B and Bel-7402, in addition to normal human hepatocyte HL-7702 cells, were purchased from the China Center for Type Culture Collection (Wuhan, China). Hep3B cells were cultured in Minimum Essential Medium (Gibco; Thermo Fisher Scientific, Inc., Waltham, MA, USA), and the other cells were cultured in RPMI-1640 medium (1X; Gibco; Thermo Fisher Scientific, Inc.) containing $10 \%$ fetal bovine serum (FBS; PAN-Biotech GmbH, Aidenbach, Germany) at $37^{\circ} \mathrm{C}$ in a humidified chamber supplemented with $5 \% \mathrm{CO}_{2}$.

Hepatocellular carcinoma tissues. A total of 45 frozen primary tumor samples and corresponding non-cancerous samples (located $>3 \mathrm{~cm}$ away from the tumor) were obtained from patients undergoing hepatectomy at The First Affiliated Hospital of Chongqing Medical University between September 2015 and March 2016. Patients (9 female and 36 male) were aged between 22 and 78 years and were at the following tumor stages: 4 cases of stage I; 10 cases of stage II; and 31 cases of stage III. Tissue samples were snap frozen in liquid nitrogen at the time of surgery and stored at $-80^{\circ} \mathrm{C}$. The tumor, node, metastasis (TNM) classification of the Union for International Cancer Control was used. None of the patients received radiotherapy or chemotherapy prior to surgery.

Reverse transcription-quantitative polymerase chain reaction (RT-qPCR) analysis. miRNA and mRNA was extracted from cell lines or tissue using Hipure Universal miRNA kit (Magen, Guangzhou, China; http://www.magentec.com.cn), according to the manufacturer's protocol. The primers for miRNA and mRNA were produced using All-in-One ${ }^{\mathrm{TM}}$ miRNA qPCR Primer and All-in-One ${ }^{\mathrm{TM}}$ mRNA qPCR Primer (GeneCopoeia, Inc., Rockville, MD, USA), and the sequences were: miR-340 forward, 5-'GCGGTTATAAAGCAATGAGA-3' and reverse, 5'-GTGCGTGTCGTGGAGTCG-3'; U6 forward, 5'-CTC GCTTCGGCAGCACA-3' and reverse, 5'-AACGCTTCA CGAATTTGCGT-3'; SKP2 forward, 5'-AGTCTCTATGGC AGACCTTAGACC-3' and reverse, 5'-TTTCTGGAGATT CTTTCTGTAGCC-3'; and GAPDH forward, 5'-CAGTCA GCCGCATCTTCTTTT-3' and reverse, 5'-GTGACCAGG CGCCCAATAC-3'. The synthesis of cDNA from miRNA and mRNA used All-in-One ${ }^{\mathrm{TM}}$ miRNA First-Strand cDNA Synthesis and All-in-One ${ }^{\mathrm{TM}}$ First-Strand cDNA Synthesis kits (GeneCopoeia, Inc.). The reaction conditions for miRNA were as follows: $37^{\circ} \mathrm{C}$ for $60 \mathrm{~min} ; 85^{\circ} \mathrm{C}$ for $5 \mathrm{~min} ; 4^{\circ} \mathrm{C}$ holding, and the reaction system had a volume of $20 \mu \mathrm{l}$. The reaction conditions for mRNA were as follows: $60^{\circ} \mathrm{C}$ for $5 \mathrm{~min}$, with a reaction system of $13 \mu \mathrm{l} ; 37^{\circ} \mathrm{C}$ for $60 \mathrm{~min} ; 85^{\circ} \mathrm{C}$ for $5 \mathrm{~min}$; $4^{\circ} \mathrm{C}$ holding, and the reaction system had a volume of $25 \mu 1$. All steps were performed according to the manufacturer's protocol. qPCR was performed in triplicate for each case using All-in-One ${ }^{\mathrm{TM}}$ miRNA kit and All-in-One ${ }^{\mathrm{TM}}$ qPCR Mix (GeneCopoeia, Inc.), respectively, on a CFX96 ${ }^{\mathrm{TM}}$ Real-Time System (Bio-Rad Laboratories, Inc., Hercules, CA, USA). The temperature protocol for the reaction was as follows: $95^{\circ} \mathrm{C}$ for $10 \mathrm{~min} ; 40$ cycles at $95^{\circ} \mathrm{C}$ for $10 \mathrm{sec}$ and $60^{\circ} \mathrm{C}$ for $20 \mathrm{sec}$, and $72^{\circ} \mathrm{C}$ for $15 \mathrm{sec}$. miRNA expression was measured using $\mathrm{Cq}$ (threshold cycle). The $2^{-\Delta \Delta \mathrm{Cq}}$ method for relative quantitation of gene expression was used to determine miRNA expression levels (17). The $\Delta \mathrm{Cq}$ was calculated by subtracting the $\mathrm{Cq}$ of U6 RNA from the Cq of the miRNA of interest. Fold changes were generated using the equation $2^{-\Delta \Delta \mathrm{Cq}}$. The expression level of U6 and GAPDH was used as the internal control for miRNA and mRNA expression, respectively.

Oligonucleotide transfection. The miR-340 mimics (pLVX-ZsGreen-Puro-miR-340), miR-340 inhibitor (pLVX-tdTomato-Puro-miR-340 inhibitor) and their controls (pLVX-ZsGreen and pLVX-tdTomato) were synthesized by GeneCopoeia, Inc. and transfected into the cells at a final oligonucleotide concentration of $1 \mu \mathrm{g} / \mathrm{ml}$. All cell transfections were performed using EndoFection ${ }^{\mathrm{TM}}$-Max (GeneCopoeia, Inc.), according to the manufacturer's protocol. The density of cells was $3 \times 10^{7}$ per 6 -well plate and subsequent experimentation was performed $48 \mathrm{~h}$ after transfected.

Cell proliferation and apoptosis. For the analysis of cell proliferation, cells were seeded into 96 -well plates at $1 \times 10^{5}$ cells/well. Cells were incubated in $10 \%$ Cell Counting kit-8 (CCK-8; Dojindo Molecular Technologies, Inc., Kumamoto, Japan) solution and $\mathrm{x}$ diluted in normal culture medium at $37^{\circ} \mathrm{C}$ until visual color conversion was apparent. The SMMC-7721 proliferation rate was determined at 24, 48 and $72 \mathrm{~h}$ following transfection. The absorbance in each well was measured with a VARIOSKAN FLASH (Thermo Fisher Scientific, Inc.) at $450 \mathrm{~nm}$. For the analysis of cellular apoptosis, cells were transfected with miR-340 mimic, miR-340 inhibitor and their corresponding control for $24 \mathrm{~h}$. Following transfection, cells were harvested and washed twice in PBS; miR-340 mimic and its control were stained with an Annexin V-phycoerythrin/7-aminoactinomycin D apoptosis kit [Multi Sciences (Lianke) Biotech. Co., Ltd., Hangzhou, China], and miR-340 inhibitor and its control was stained with Annexin V-fluorescein isothiocyanate/propidium iodide apoptosis kit [Multi Sciences (Lianke) Biotech. Co., Ltd.], following the manufacturer's protocol, using a BD Influx Flow Cytometer $\&$ Cell Sorter and the results were analyzed using BD FACS software version 1.0 (BD Biosciences, Franklin Lake, NJ, USA).

Transwell invasion assay. For analysis of cell migration and invasion, Transwell chambers $(8-\mu \mathrm{m}$ pore size; EMD Millipore, Billerica, MA, USA) and Matrigel (diluted 1:9) (Corning Incorporated, Corning, NY, USA) was used. Cells were incubated at $37^{\circ} \mathrm{C}$ on 6 -well plates for $8 \mathrm{~h}$ A total of $12 \mathrm{~h}$ subsequent to transfection, cells were starved for $12 \mathrm{~h}$. For migration assay, $2 \times 10^{5}$ cells were suspended in $200 \mu \mathrm{l}$ serum-free RPMI-1640 and seeded in the top chamber, and $350 \mu \mathrm{l}$ RPMI-1640 containing 10\% FBS was added to the lower chamber. For invasion assay, following the above process the Matrigel on the top of chamber was allowed to solidify ( $\sim 5 \mathrm{~h}$ at $37^{\circ} \mathrm{C}$ ). Following migration or invasion assay was $24 \mathrm{~h}$ of incubation at $37^{\circ} \mathrm{C}$ in a $5 \% \mathrm{CO}_{2}$ atmosphere, after which the cells on the upper surface of the membrane were removed and fixed 


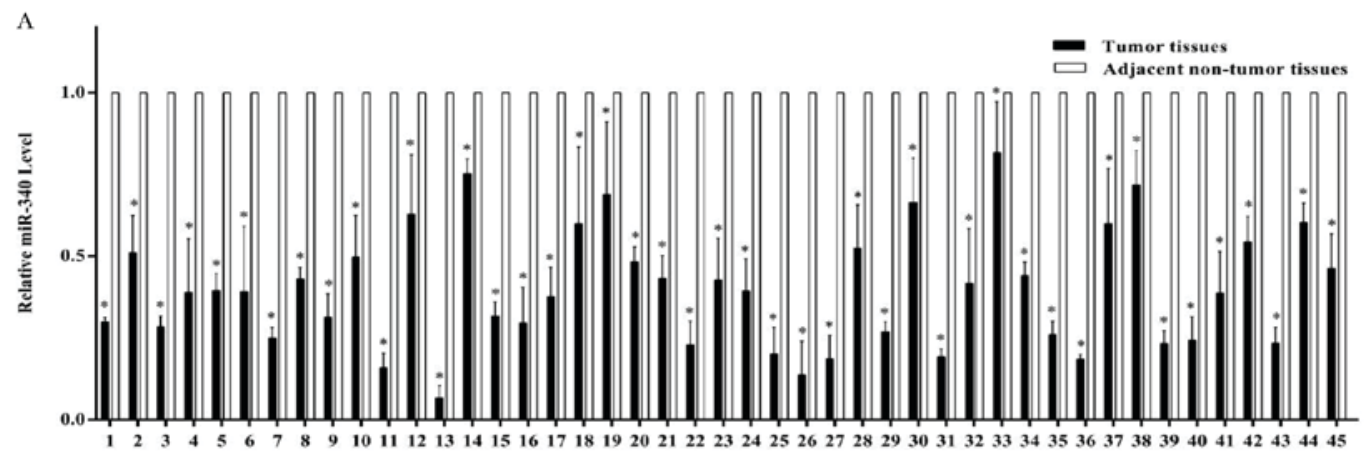

B

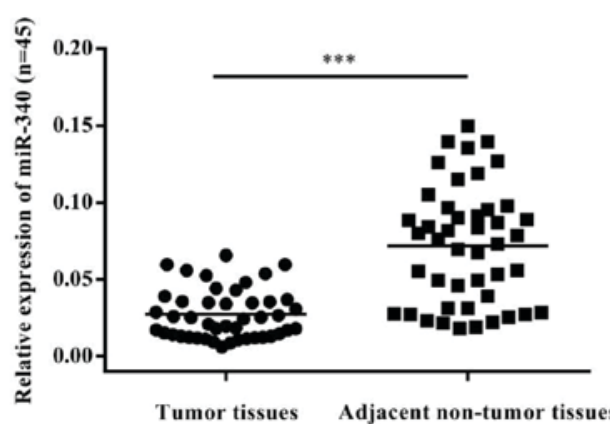

C

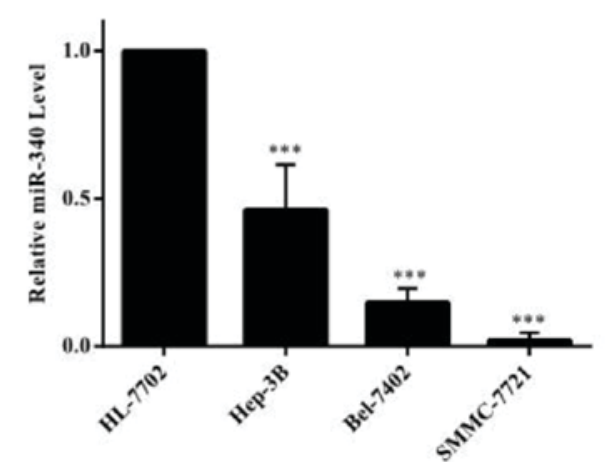

Figure 1. Expression of miR-340 in patients with HCC and cell lines. (A) miR-340 was detected in 45 pairs of HCC tissues and its adjacent normal controls by RT-qPCR analysis. (B) Relative miR-340 expression levels in HCC tissues and adjacent normal tissues were determined by RT-qPCR analysis. Levels of miR-340 in HCC tissues were significantly decreased compared with corresponding adjacent non-tumor tissues. (C) Downregulation of miR-340 expression was observed in HCC cell lines. Relative expression of miR-340 in three HCC cell lines (Hep-3B, Bel-7402 and SMMC-7721) and one normal human hepatocyte cell line (HL-7702) was determined by RT-qPCR analysis. U6 spliceosomal RNA was detected as a loading control. Data are presented as the mean \pm standard deviation. ${ }^{*} \mathrm{P}<0.05,{ }^{* * *} \mathrm{P}<0.001$ vs. respective controls. HCC, hepatocellular carcinoma; RT-qPCR, reverse transcription-quantitative polymerase chain reaction; $\mathrm{miR}$, microRNA.

in $4 \%$ paraformaldehyde $\sim 30 \mathrm{~min}$, followed by staining with $0.5 \%$ crystal violet $\sim 60 \mathrm{~min}$, all at $25^{\circ} \mathrm{C}$. Cells were counted using an upright microscope (Ci-L; Nikon Corporation, Tokyo, Japan; magnification, x200).

Western blotting. Prior to extracting the protein, SMMC-7721 cells were incubated at $37^{\circ} \mathrm{C}$ on 6 -well plates for $48 \mathrm{~h}$ following transfection. Cells were washed twice in cold PBS and lysed in radioimmunoprecipitation assay lysis buffer (Beyotime Institute of Biotechnology, Haimen, China) with protease inhibitor cocktail (Beyotime Institute of Biotechnology). The protein concentration of cell lysates was quantified using a bicinchoninic acid kit (Beyotime Institute of Biotechnology), and equal quantities (30 $\mu \mathrm{g})$ of protein were separated using SDS-PAGE on $10 \%$ gels, followed by transfer to a polyvinylidene fluoride membrane (EMD Millipore). The membranes were blocked in $8 \%$ skimmed milk diluted with TBS with Tween-20 [Tris-HCl $24.23 \mathrm{~g} / 1, \mathrm{NaCl} 80.06 \mathrm{~g} / \mathrm{l}(\mathrm{pH} 7.5)$, and $0.1 \%$ Tween $(1 \mathrm{ml})]$ at room temperature for $1 \mathrm{~h}$ and incubated overnight at $4^{\circ} \mathrm{C}$ with primary anti-SKP2 antibody (RLT-4311) or primary anti-GAPDH antibody (RLM-3215; both 1:500; Ruiyingbio, Suzhou, China). The membranes were subsequently incubated with goat anti-rabbit IgG secondary antibody (RS0002) conjugated to horseradish peroxidase (HRP; 1:5,000; Ruiyingbio) for $3 \mathrm{~h}$ at $25^{\circ} \mathrm{C}$. The proteins were visualized using Chemiluminescent HRP Substrate (EMD Millipore). The density was measured using Image $\mathrm{Lab}^{\mathrm{TM}}$ Software version 4.1 (Bio-Rad Laboratories, Inc.), and values were normalized to the densitometric values of GAPDH in each sample.

Online prediction for miRNA target genes. Using online prediction software for miRNA target genes, including PicTar (http://pictar.mdc-berlin.de/), miRanda (http://www. microrna.org/microrna/home.do) and Targetscan (http://www. targetscan.org/vert_71/).

Statistical analysis. Each experiment was repeated at least three times. Data are presented as the mean \pm standard deviation. Statistical analyses were performed using Student's t-test, differences among groups were analyzed using one-way analysis of variance followed by least significant difference post hoc analysis, and the associations between miR-340 expression and clinical pathological factors were analyzed using the $\chi^{2}$ test. $\mathrm{P}<0.05$ was considered to indicate a statistically significant difference. All statistical analyses were performed using SPSS 19.0 software (IBM Corp., Armonk, NY, USA).

\section{Results}

Expression of miR-340 in clinical patients with HCC and $H C C$ cell lines. In order to examine the expression of miR-340 in HCC, the expression of miR-340 in the normal hepatocyte line HL-7702 and hepatocellular carcinoma cell lines Hep3B, SMMC-7721 and Bel-7402 was determined (Fig. 1). Compared 
with HL-7702, RT-qPCR analysis revealed that the expression of miR-340 was decreased in the three hepatocellular carcinoma cell lines (Fig. 1C). In tissues, it was observed that the miR-340 level in tumor tissues was consistently decreased compared with adjacent non-tumor tissues (Fig. 1A). It was observed that the expression of miR-340 in tumor tissues was significantly decreased compared with adjacent non-tumor tissues (Fig. 1B). Further analysis demonstrated that patients with $\mathrm{HCC}$ who were hepatitis B virus $(\mathrm{HBV})^{+}$or exhibited copy numbers of HBV DNA $>1.0 \times 10^{3}$ had decreased expression of miR-340. In addition, the miR-340 level was decreased in patients who with larger tumor sizes $(\geq 5 \mathrm{~cm})$ and higher TNM grades (Table I). The results of the present study demonstrated that miR-340 may be a tumor suppressor which is associated with HCC pathogenesis, and miR-340 may correlate with disease severity.

miR-340 inhibits HCC cell proliferation and induces apoptosis. Using RT-qPCR analysis, the expression of miR-340 in SMMC-7721 following transfection was confirmed. The results of the present study demonstrated that the expression of miR-340 in SMMC-7721 cells transfected with the miR-340 mimic was increased compared with the miR-340 mimic control. Following transfection of the miR-340 inhibitor and miR-340 inhibitor control, the expression of the latter was increased compared with the former (Fig. 2A). The CCK-8 assay demonstrated that the proliferation of SMMC-7721 cells transfected with miR-340 mimic was significantly decreased compared with the miR-340 mimic control group (Fig. 2B). Simultaneously, the proliferation ratio of SMMC-7721 cells transfected with miR-340 inhibitor was significantly increased compared with the miR-340 inhibitor control group (Fig. 2C). Using flow cytometry, it was observed that the apoptosis ratio of SMMC-7721 cells transfected with miR-340 mimic was significantly increased than miR-340 mimic control group (Fig. 2D-F); however, the apoptosis ratio of SMMC-7721 cells transfected with miR-340 inhibitor was significantly decreased compared with the miR-340 inhibitor control (Fig. 2G-I). The results of the present study demonstrated that miR-340 was able to repress cell proliferation and induce apoptosis.

miR-340 inhibits HCC cell migration and invasion. Using a Transwell invasion assay, it was observed that the migration of SMMC-7721 cells with miR-340 mimics significantly decreased compared with the miR-340 mimic control group, while the migration of SMMC-7721 cells transfected with miR-340 inhibitor increased compared with the miR-340 inhibitor control group (Fig. 3A-C). Following injection of the Matrigel into the chamber, the invasiveness of SMMC-7721 cells transfected with miR-340 mimic was decreased compared with the miR-340 mimic control group. In addition, the invasiveness of cells transfected with miR-340 inhibitor was increased compared with the miR-340 inhibitor control group (Fig. 3D-F). Therefore, miR-340 was able to inhibit migration and invasion in the SMMC-7721 cell line.

miR-340 downregulates the expression of SKP2. Online prediction software indicated that SKP2, which is associated with cell proliferation and apoptosis, is a target gene of miR-340. Bioinformatic analysis demonstrated that the SKP2
Table I. Association between miR-340 expression and clinicopathological features.

\begin{tabular}{|c|c|c|c|c|}
\hline \multirow[b]{2}{*}{ Feature } & \multirow{2}{*}{$\begin{array}{l}\text { No. patients } \\
\quad(\mathrm{n}=45)\end{array}$} & \multicolumn{2}{|c|}{$\begin{array}{c}\text { miR-340 } \\
\text { expression }\end{array}$} & \multirow[b]{2}{*}{ P-value } \\
\hline & & Low & High & \\
\hline \multicolumn{5}{|l|}{ Age, years } \\
\hline$<40$ & 5 & 3 & 2 & \multirow[t]{2}{*}{0.751} \\
\hline$\geq 40$ & 40 & 21 & 19 & \\
\hline \multicolumn{5}{|l|}{ Sex } \\
\hline Male & 36 & 21 & 15 & \multirow[t]{2}{*}{0.179} \\
\hline Female & 9 & 3 & 6 & \\
\hline \multicolumn{5}{|l|}{ HBsAg } \\
\hline+ & 32 & 21 & 11 & \multirow[t]{2}{*}{0.010} \\
\hline- & 13 & 3 & 10 & \\
\hline \multicolumn{5}{|l|}{ HBV DNA } \\
\hline$<1.0 \times 10^{3}$ & 23 & 7 & 16 & \multirow[t]{2}{*}{0.002} \\
\hline$\geq 1.0 \times 10^{3}$ & 22 & 17 & 5 & \\
\hline \multicolumn{5}{|l|}{ AFP, $\mu \mathrm{g} / 1$} \\
\hline$<400$ & 33 & 15 & 18 & \multirow[t]{2}{*}{0.079} \\
\hline$\geq 400$ & 12 & 9 & 3 & \\
\hline \multicolumn{5}{|l|}{ ALT, U/1 } \\
\hline$<40$ & 19 & 11 & 8 & \multirow[t]{2}{*}{0.600} \\
\hline$\geq 40$ & 26 & 13 & 13 & \\
\hline \multicolumn{5}{|l|}{ AST, U/1 } \\
\hline$<40$ & 15 & 8 & 7 & \multirow[t]{2}{*}{1.000} \\
\hline$\geq 40$ & 30 & 16 & 14 & \\
\hline \multicolumn{5}{|c|}{ Tumor size, cm } \\
\hline$<5$ & 13 & 2 & 11 & \multirow[t]{2}{*}{0.001} \\
\hline$\geq 5$ & 32 & 22 & 10 & \\
\hline \multicolumn{5}{|l|}{ Cirrhosis } \\
\hline Yes & 32 & 20 & 12 & \multirow[t]{2}{*}{0.053} \\
\hline No & 13 & 4 & 9 & \\
\hline \multicolumn{5}{|c|}{ TNM staging } \\
\hline I & 4 & 0 & 4 & \multirow[t]{3}{*}{0.002} \\
\hline II & 10 & 2 & 8 & \\
\hline III & 31 & 22 & 9 & \\
\hline
\end{tabular}

HBsAG, Australia antigen; HBV, hepatitis $\mathrm{B}$ virus; AFP, alpha-fetoprotein; ALT, alanine aminotransferase; AST, aspartate aminotransferase; TNM, tumor, node, metastasis; miR, microRNA.

3' untranslated region (UTR) contains a seed sequence which complements miR-340. This suggested that miR-340 may bind strongly to the SKP2 3'UTR (Fig. 4A). Using RT-qPCR analysis, it was observed that the level of SKP2 mRNA was decreased following transfection of miR-340 mimic into SMMC-7721 cells; by contrast, transfecting miR-340 inhibitor into SMMC-7721 cells was able to increase the level of SKP2 mRNA (Fig. 4B). The protein level of SKP2 was detected by western blotting (Fig. 4C). Compared with the corresponding control group, miR-340 mimic inhibited the level of SKP2; by contrast, miR-340 inhibitor increased the level of SKP2 


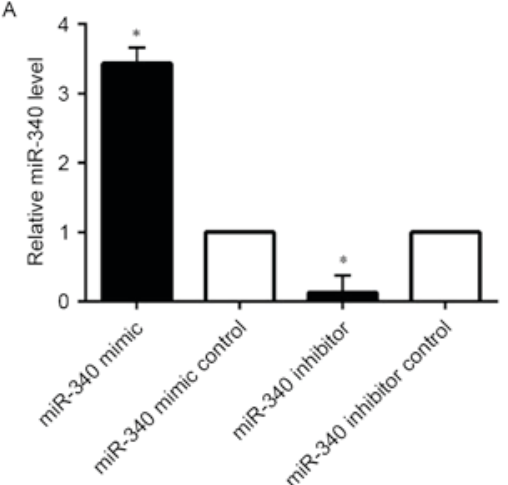

D

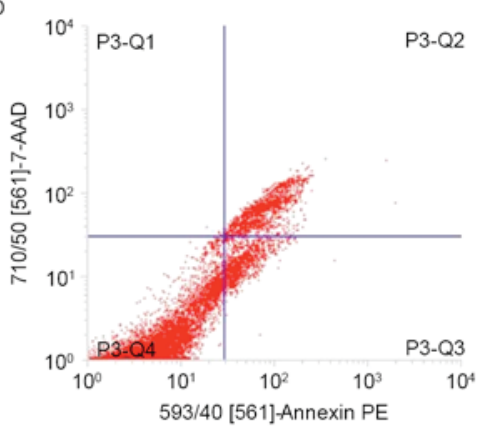

G

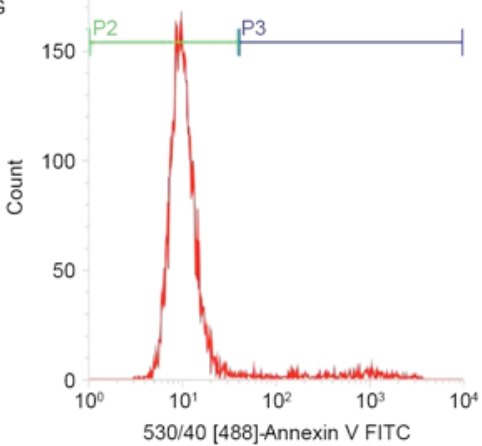

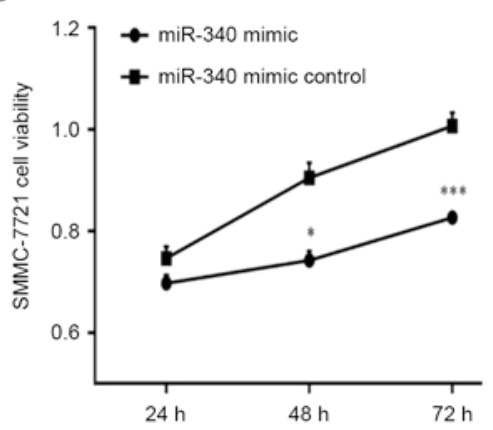

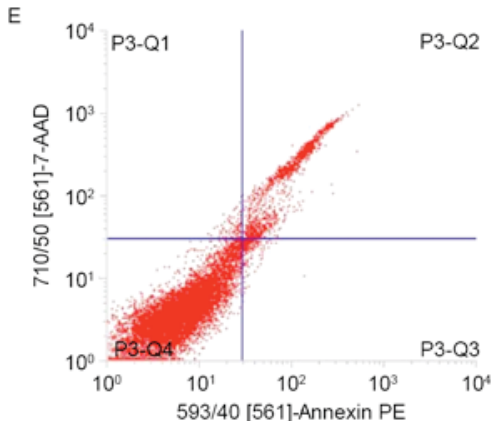

H

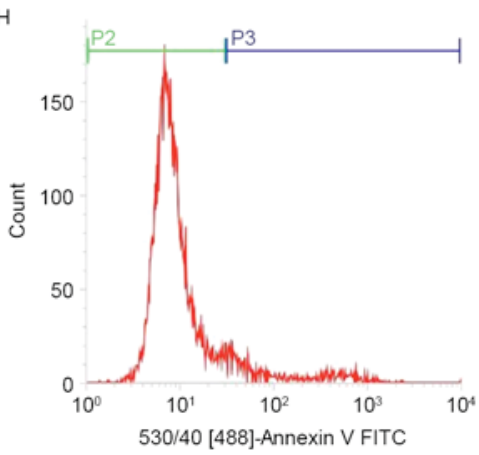

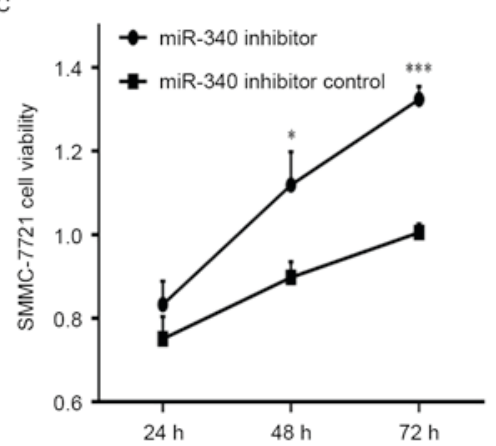
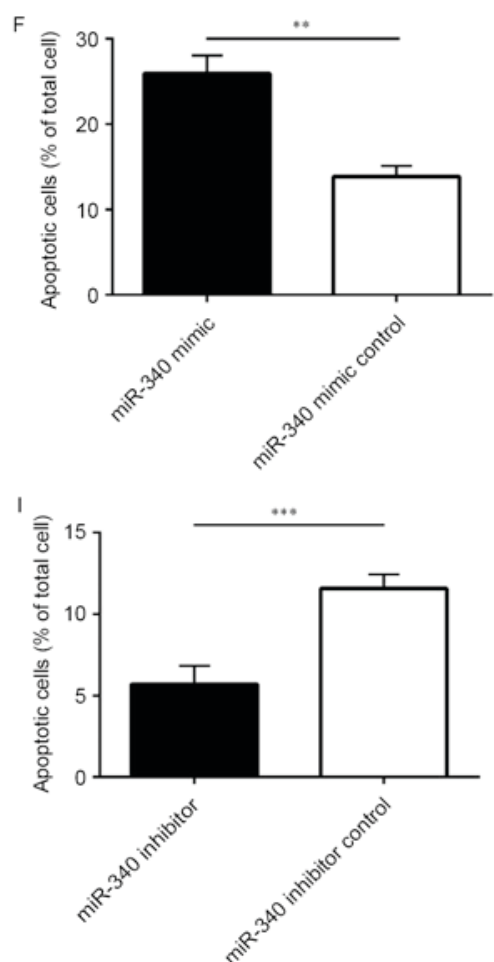

Figure 2. miR-340 inhibits HCC cell proliferation and induces apoptosis. (A) Reverse transcription-quantitative polymerase chain reaction analysis of miR-340 in SMMC-7721 cells upon transfection with miR-340. The expression of miR-340 in SMMC-7721 cells transfected with miR-340 mimics was upregulated, and was downregulated in cells transfected with miR-340 inhibitor. U6 spliceosomal RNA was used as an internal control. (B) Overexpression of miR-340 significantly inhibited the viability of SMMC-7721 cells at different time points. (C) Suppression of miR-340 significantly increased the viability of SMMC-7721 cells at different time points. (D) Apoptosis cells of miR-340 mimic. (E) Apoptosis cells of miR-340 mimic control. (F) Apoptosis cells were significantly upregulated by overexpression of miR-340 compared with miR-340 mimic control. (G) Apoptosis cells of miR-340 inhibitor. (H) Apoptosis cells of miR-340 inhibitor control. (I) Apoptotic cells were significantly decreased by suppression of miR-340 compared with miR-340 inhibitor control. Data are presented as the mean \pm standard deviation. ${ }^{*} \mathrm{P}<0.05,{ }^{* *} \mathrm{P}<0.01$ and ${ }^{* * *} \mathrm{P}<0.001$ vs. respective control. miR, microRNA; HCC, hepatocellular carcinoma; $\mathrm{PE}$, phycoerythrin; 7-AAD, 7-aminoactinomycin.

(Fig. 4D). Therefore, miR-340 was able to influence the expression of SKP2.

\section{Discussion}

Considering the importance of miRNAs in the post-transcriptional regulation gene expression, a number of studies have demonstrated their role in human carcinogenesis. Previously, the function of miRNA in tumors has been elucidated, and it has been demonstrated that miRNAs may be either oncogenic or anti-oncogenic, acting as therapeutic targets and prognostic tools $(10,18)$. In the present study, a novel cancer suppressor, miR-340, was identified in human HCC. It was observed that the expression of miR-340 was decreased in three human HCC cell lines compared with normal human hepatocytes. Simultaneously, miR-340 was detected to be downregulated in 45 pairs of HCC tissues compared with adjacent normal controls. Statistical analysis demonstrated that the miR-340 level was decreased in tumor tissues compared with corresponding adjacent non-tumor tissues. Patients with $\mathrm{HCC}$ who were $\mathrm{HBV}^{+}$or exhibited copy numbers of HBV DNA $>1.0 \times 10^{3}$ had decreased expression of miR-340. In addition, the miR-340 level was decreased in patients with larger tumor sizes $(\geq 5 \mathrm{~cm})$ and higher TNM grades. The results of the present study demonstrated that the expression of miR-340 may be associated with HBV infection. A previous study reported that $\mathrm{HBV} X$ protein may activate nuclear factor- $\kappa \mathrm{B}$, which may combine with the 

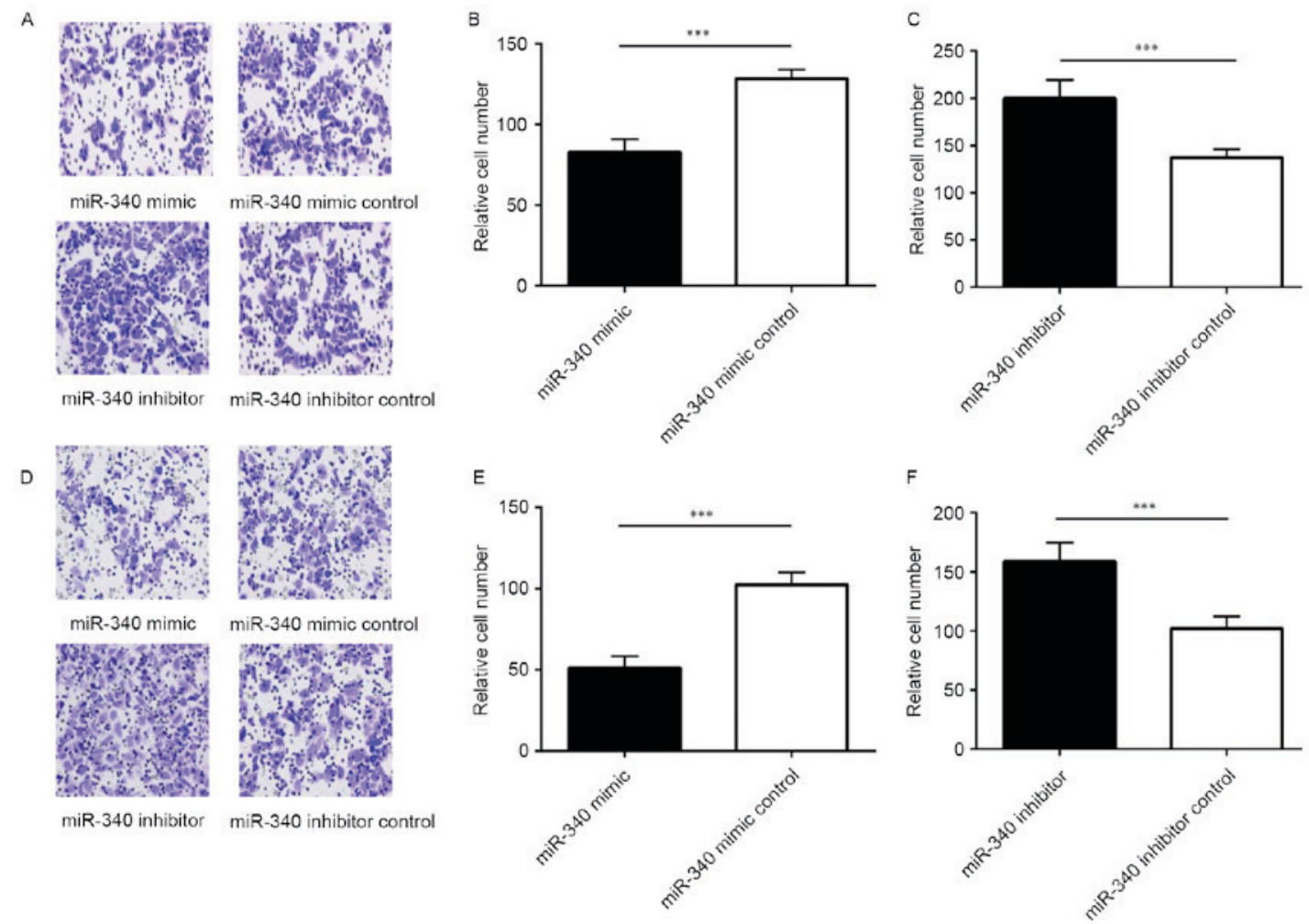

Figure 3. Overexpression of miR-340 inhibits the migration and invasion of SMMC-7721 cells. (A) miR-340 decreased the migratory abilities of SMMC-7721 cells. The relative ratio of migratory cells per field is presented for cells transfected with (B) miR-340 mimic and control, and (C) miR-340 inhibitor and control. (D) miR-340 decreased the invasive abilities of SMMC-7721 cells. The relative ratio of invasive cells per field is presented for cells transfected with (E) miR-340 mimic and control, and (F) miR-340 inhibitor and control. Magnification, x200. Data are presented as the mean \pm standard deviation. ${ }^{* * *} \mathrm{P}<0.001$ vs. respective control. miR, microRNA.

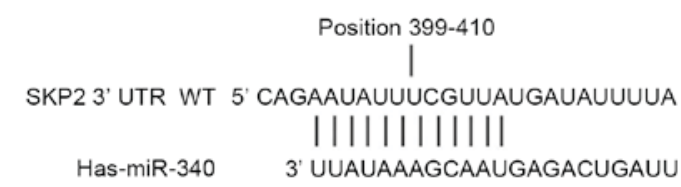

SKP2 3' UTR MUT 5' CAGUUAUAAAGCAAUgagaAUUUUA

C

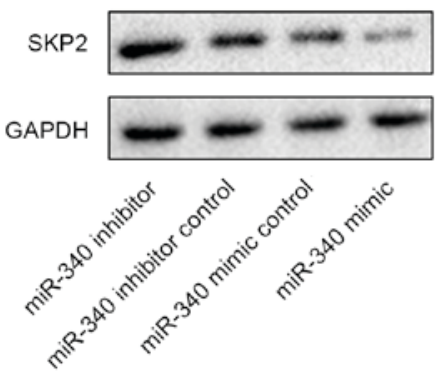

B

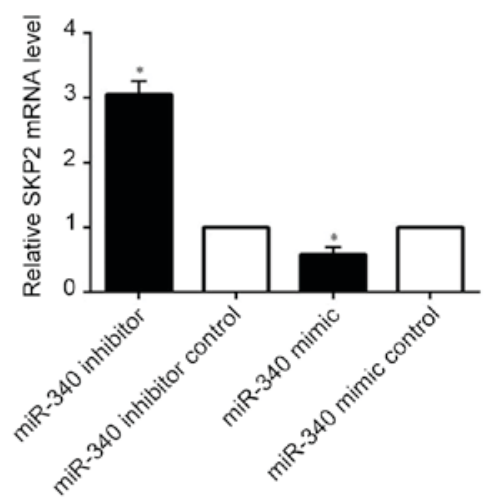

$\mathrm{D}$

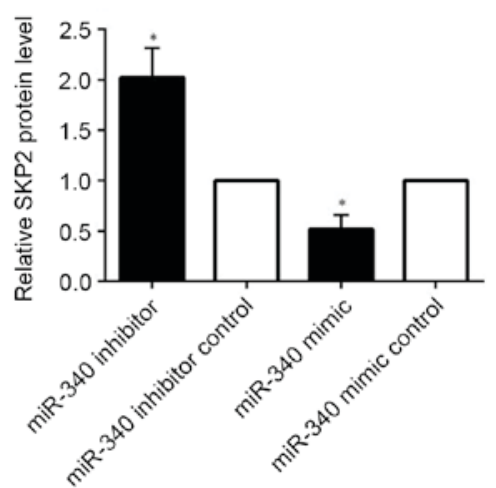

Figure 4. miR-340 downregulates SKP2 via interaction with its 3'UTR. (A) Online prediction software revealed that SKP2 mRNA contained an miR-340 seed match at position 399-410 of the SKP2 3'UTR. (B) Reverse transcription-quantitative polymerase chain reaction analysis was performed to examine the effects of miR-340 on SKP2 expression in SMMC-7721 cells. Ectopic expression of miR-340 significantly decreased the number of SKP2 mRNA transcripts. GAPDH was used as an internal control. (C) Western blot analysis and (D) quantification revealed that SKP2 was significantly downregulated in SMMC-7721 cells following transfection with miR-340, and upregulated by transfection with miR-340 inhibitor. Data are presented as the mean \pm standard deviation. ${ }^{*} \mathrm{P}<0.05$ vs. respective control. UTR, untranslated region; SKP2, S-phase kinase-associated protein 2; miR, microRNA. 
promoter region or enhancement region of miRNA to induce transactivation (19). Therefore, further studies are required to verify the association between miR-340 and HBV infection. miR-340 significantly suppressed SMMC-7721 proliferation and induced apoptosis. The results of the present study indicated that miR-340 suppressed migration and invasion in HCC cell lines. SKP2 was considered to be a potential target of miR-340. A previous study detected the overexpression of SKP2 in late-stage HCC, and overexpression predicted poor survival outcomes (20). Consequently, the present study aimed to investigate whether miR-340 may suppress the expression of SKP2. Using RT-qPCR and western blot analyses, it was observed that upregulating the expression of miR-340 may inhibit SKP2 mRNA and protein expression, while downregulating the expression of miR-340 increased its expression at the mRNA and protein levels. However, the mechanism underlying the overexpression of SKP2 regulated by miR-340 requires further investigation.

The antitumor effect of miR-340 has been previously identified. As a tumor suppressor, the expression of the miRNA may be increased in adjacent normal tissues compared with tumor tissue, in addition to in normal cell lines compared with cancer cell lines. miR-340 has been detected at a lower expression level in tumor tissues compared with adjacent normal tissues, in addition to in cancer cell lines compared with normal cell lines, including osteosarcoma, glioblastoma and liver metastasis of colorectal cancer; in addition, the miR-340 expression level in these types of cancer may predict tumor progression and prognosis $(11,21,22)$. Notably, in melanoma, miR-340 acts as a tumor suppressor although its expression in melanoma cell lines is increased compared with normal melanocyte cell lines (23). This previous result indicated that the roles of miR-340 may not be consistent with the pattern of its expression in melanoma cells; consequently, when assessing the function of a miRNA, the level of its expression may not be the sole consideration. miR-340 is involved in oncogenesis in various ways; miR-340 inhibits proliferation, migration and invasion, and induces apoptosis, in ovarian cancer, prostate cancer, laryngeal squamous cell carcinoma and glioblastoma $(12,22,24-26)$. The results of the present study demonstrated the same function of miR-340 in HCC compared with these previous studies. miR-340 has been demonstrated to mediate glycometabolism by down-regulating glucose transporter-1 in oral squamous cell carcinoma (16) and accelerating the transformation of pyruvate kinase PKM (PKM)2 to PKM1, and the PKM1/PKM2 ratio is able to repress the rate of glycolysis in colorectal cancer (15), ultimately resulting in resistance to the Warburg effect. Whether this resistance presents in HCC requires further study. Overexpression of miR-340 was demonstrated to reduce the expression of mesenchymal phenotypic markers while increasing the expression of epithelial phenotypic markers, thereby inhibiting EMT in breast cancer cells (27). Autophagy may be observed in a number of physiological and pathological conditions, and it has been reported that miR-340 is able to repress E3 ubiquitin-protein ligase XIAP, which is an important anti-autophagy factor in tumor cells, and thereby promotes autophagy $(22,28)$.

miR-340 serves important roles in carcinogenesis, and the results of the present study indicated that miR-340 inhibits
HCC cell proliferation, migration and invasion, in addition to inducing apoptosis. The mechanism underlying the function of miR-30 in HCC may be accounted for by the downregulation of SKP2, which requires further study. Due to the differential expression of miR-340 in HCC tumor tissues compared with normal adjacent tissues, it may be suggested that miR-340 may have potential for predicting tumor progression and prognosis.

\section{References}

1. Torre LA, Bray F, Siegel RL, Ferlay J, Lortet-Tieulent J and Jemal A: Global cancer statistics, 2012. CA Cancer J Clin 65: 87-108, 2015.

2. McGlynn KA, Petrick JL and London WT: Global epidemiology of hepatocellular carcinoma: An emphasis on demographic and regional variability. Clin Liver Dis 19: 223-238, 2015.

3. Zucman-Rossi J, Villanueva A, Nault JC and Llovet JM: Genetic landscape and biomarkers of hepatocellular carcinoma. Gastroenterology 149: 1226-1239.e4, 2015.

4. Szabo G and Bala S. MicroRNAs in liver disease. Nat Rev Gastroenterol Hepatol 10: 542-552, 2013.

5. Bartel DP: MicroRNAs: Genomics, biogenesis, mechanism, and function. Cell 116: 281-297, 2004.

6. Wu SY, Lan SH and Liu HS: Autophagy and microRNA in hepatitis B virus-related hepatocellular carcinoma. World J Gastroenterol 22: 176-187, 2016.

7. Zhang J and Ma L: MicroRNA control of epithelial-mesenchymal transition and metastasis. Cancer Metastasis Rev 31: 653-662, 2012.

8. de Cedrón MG and de Molina AR: Microtargeting cancer metabolism: Opening new therapeutic windows based on lipid metabolism. J Lipid Res 57: 193-206, 2016.

9. Peschansky VJ and Wahlestedt C: Non-coding RNAs as direct and indirect modulators of epigenetic regulation. Epigenetics 9: 3-12, 2014.

10. Callegari E, Elamin BK, Sabbioni S, Gramantieri L and Negrini M: Role of microRNAs in hepatocellular carcinoma: A clinical perspective. Onco Targets Ther 6: 1167-1178, 2013.

11. Takeyama H, Yamamoto H, Yamashita S, Wu X, Takahashi H, Nishimura J, Haraguchi N, Miyake Y, Suzuki R, Murata K, et al: Decreased miR-340 expression in bone marrow is associated with liver metastasis of colorectal cancer. Mol Cancer Ther 13: 976-985, 2014.

12. Li P, Sun Y and Liu Q: MicroRNA-340 induces apoptosis and inhibits metastasis of ovarian cancer cells by inactivation of NF-x03BA;B1. Cell Physiol Biochem 38: 1915-1927, 2016.

13. Mohammadi-Yeganeh S, Paryan M, Arefian E, Vasei M, Ghanbarian H, Mahdian R, Karimipoor M and Soleimani M: MicroRNA-340 inhibits the migration, invasion, and metastasis of breast cancer cells by targeting Wnt pathway. Tumour Biol 37: 8993-9000, 2016.

14. Fernandez S, Risolino M, Mandia N, Talotta F, Soini Y, Incoronato M, Condorelli G, Banfi S and Verde P: miR-340 inhibits tumor cell proliferation and induces apoptosis by targeting multiple negative regulators of p27 in non-small cell lung cancer. Oncogene 34: 3240-3250, 2015.

15. Sun Y, Zhao X, Zhou Y and Hu Y: miR-124, miR-137 and miR-340 regulate colorectal cancer growth via inhibition of the Warburg effect. Oncol Rep 28: 1346-1352, 2012.

16. Xu P, Li Y, Zhang H, Li M and Zhu H: MicroRNA-340 mediates metabolic shift in oral squamous cell carcinoma by targeting glucose transporter-1. J Oral Maxillofac Surg 74: 844-850, 2016.

17. Livak KJ and Schmittgen TD: Analysis of relative gene expression data using real-time quantitative PCR and the 2(-Delta Delta C(T)) method. Methods 25: 402-408, 2001.

18. Negrini M, Ferracin M, Sabbioni S and Croce CM: MicroRNAs in human cancer: From research to therapy. J Cell Sci 120: 1833-1840, 2007.

19. Zhang X, Liu S, Hu T, Liu S, He Y and Sun S: Up-regulated microRNA-143 transcribed by nuclear factor kappa B enhances hepatocarcinoma metastasis by repressing fibronectin expression. Hepatology 50: 490-499, 2009.

20. Lee SW, Li CF, Jin G, Cai Z, Han F, Chan CH, Yang WL, Li BK, Rezaeian AH, Li HY, et al: Skp2-dependent ubiquitination and activation of LKB1 is essential for cancer cell survival under energy stress. Mol Cell 57: 1022-1033, 2015. 
21. Cai H, Lin L, Cai H, Tang $M$ and Wang Z: Combined microRNA-340 and ROCK1 mRNA profiling predicts tumor progression and prognosis in pediatric osteosarcoma. Int J Mol Sci 15: 560-573, 2014

22. Huang D, Qiu S, Ge R, He L, Li M, Li Y and Peng Y: miR-340 suppresses glioblastoma multiforme. Oncotarget 6: 9257-9270, 2015.

23. Poenitzsch Strong AM, Setaluri V and Spiegelman VS MicroRNA-340 as a modulator of RAS-RAF-MAPK signaling in melanoma. Arch Biochem Biophys 563: 118-124, 2014.

24. Huang K, Tang Y, He L and Dai Y: MicroRNA-340 inhibits prostate cancer cell proliferation and metastasis by targeting the MDM2-p53 pathway. Oncol Rep 35: 887-895, 2016.
25. Wei P, Qiao B, Li Q, Han X, Zhang H, Huo Q and Sun J: microRNA-340 suppresses tumorigenic potential of prostate cancer cells by targeting high-mobility group nucleosome-binding domain 5. DNA Cell Biol 35: 33-43, 2016.

26. Yu W, Zhang G, Lu B, Li J, Wu Z, Ma H, Wang H and Lian R MiR-340 impedes the progression of laryngeal squamous cell carcinoma by targeting EZH2. Gene 577: 193-201, 2016.

27. Hou LK, Yu Y, Xie YG, Wang J, Mao JF, Zhang B, Wang X and Cao XC: miR-340 and ZEB1 negative feedback loop regulates TGF- $\beta$ - mediated breast cancer progression. Oncotarget 7 : 26016-26026, 2016.

28. Huang X, Wu Z, Mei Y and Wu M: XIAP inhibits autophagy via XIAP-Mdm2-p53 signalling. EMBO J 32: 2204-2216, 2013. 